\title{
Maternal Dietary Intake and Anthropometric Measurements of Newborn at Birth
}

\author{
Fareeha Shaikh ${ }^{*}$, , Fariha Zeeshan $^{2}$, Rubina Hakeem ${ }^{2,3}$, Abdul Basit ${ }^{2}$, Asher Fawwad ${ }^{2}$ and \\ Akhtar Hussain ${ }^{1}$
}

${ }^{I}$ Faculty of Medicine, Institute of Health and Society, Department of International Community Health, University of Oslo, Norway

${ }^{2}$ Baqai Institute of Diabetology and Endocrinology, Baqai Medical University, Plot No. 1-2, II-B, Nazimabad No. 2, Karachi-74600, Pakistan

${ }^{3}$ Taibah University, Madinah Almuawwara, Saudi Arabia

\begin{abstract}
Objective: To determine the association between maternal dietary intake and nutritional status during pregnancy with anthropometric measurements of the newborns at birth.

Methods: An observational study was conducted in Karachi, Pakistan from December 2009 to April 2010. Expectant mothers were recruited from selected antenatal clinics after obtaining informed consent. On the basis of the expected weight-for-height of adult women during pregnancy, mothers were categorized into under- and well-nourished groups. Dietary profile of 100 mothers (48 from $1^{\text {st }}$ trimester and 52 from $3^{\text {rd }}$ trimester) was recorded by using "Food Frequency Questionnaire and 24 hour dietary recall”. Deliveries of $3^{\text {rd }}$ trimester group of mothers were followed. Anthropometric measurements of newborns were recorded.

Results: Dietary profile of mothers showed that most of the mothers, regardless of trimester and nutritional status were consuming less than the recommended dietary intake. Fruit and vegetable intake was very low, pertaining to $96 \%$ and $93 \%$ of mothers respectively. Eighty percent mothers were consuming less than a serving of meat per day whereas $94 \%$ had low milk consumption per day. A significant negative association was noted between milk intake in well-nourished group and sub scapular skin fold thickness of the newborns at birth. Similarly, consumption of milk in undernourished mothers was also found associated negatively with mid upper arm circumference of the newborns $(\mathrm{p}<0.05)$.
\end{abstract}

Conclusion: Overall energy intake was low in undernourished compared to well-nourished mothers during early gestation. Moreover, maternal dietary intake and nutritional status during pregnancy have impact on fetal body composition.

Keywords: Anthropometric measurements, maternal diet, newborn, nutritional status, Pakistan.

\section{INTRODUCTION}

Nutritional future of a child is highly dependent on maternal nutritional status in pregnancy [1]. Mother's nutritional status is a major determinant of not only the health outcome but also chronic disease risk in a newborn during both childhood and adult life [2]. Unfortunately, in developing countries, pregnant females are nutritionally the most insecure group and a large number of expectant mothers do not receive optimum level of essential nutrients during their gestational period [3]

One of the major consequences of poor maternal health and dietary practices is low birth weight of babies [4]. It has been estimated that prevalence of neonates born with low birth weight in the world is $15.5 \%$ [5]. Moreover, their

Address correspondence to this author at the Faculty of Medicine, Institute of Health and Society, Department of International Community Health, University of Oslo, P.O Box 1130 Blindern, N- 0317, Oslo, Norway;

Tel: 9221 36688897, 9221 36608565, 9221 36707179; Fax: 9221 36608568;

E-mail: research@bideonline.com prevalence is two times higher in underdeveloped compared to developed countries and about half of these under weight babies born in South East Asian countries [6, 7]. Moreover, birth weight has been proven a strong predictor of immune response in later life of an individual [8].

A study from developed countries projected that low birth weight is associated with inadequate contribution of carbohydrate in dietary energy [9]. Similarly, a study showed that average diet of pregnant females was deficient in terms of most of the micronutrients [10].

Likewise, various studies have been conducted among Indo-Pak population to explore the relationship between maternal anthropometric and dietary parameters with birth size of neonates. A study from India reported significant association of maternal nutrient intake and anthropometric characteristic with birth weight of neonates [11]. Majority of the studies on the relation between maternal size and nutrition with neonatal size have used only weight of the newborn as a parameter of fetal growth. It is apparent that other measurement of fetal size such as length, mid upper 
arm and head circumference may be important in predicting the outcome of fetal growth. Hence, a study was designed to highlight the relationship between maternal dietary intake and nutritional status during pregnancy with anthropometric measurements of the newborns at birth.

\section{METHODOLOGY}

An observational study was conducted in Karachi, Pakistan from December 2009 to April 2010. The study was approved by the Institutional Review Board of Baqai Institute of Diabetology and Endocrinology. One hundred expectant mothers $\left(48\right.$ from $1^{\text {st }}$ trimester and 52 from $3^{\text {rd }}$ trimester) were recruited from multiple antenatal clinics of privately practicing obstetricians after obtaining written consent.

Expectant mothers with singleton pregnancy in which conception occurred without treatment for infertility, no previous history of pregnancy induced hypertension, diabetes and/or congenital malformations were considered eligible to participate. Females having gestational diabetes and premature deliveries (gestation $<37$ weeks) were excluded from the study. Mothers were interviewed on their first visit to the antenatal clinic. Demographic, obstetric and socioeconomic information was collected through structured questionnaire. Duration of gestation in study subjects was calculated from the first day of last menstrual cycle, supported by ultrasound measurements. Deliveries of $3^{\text {rd }}$ trimester group of mothers were followed and anthropometric measurements of their newborns were recorded within $24 \mathrm{hrs}$ of birth.

\section{Maternal Nutritional Status}

Height of mothers was measured in centimeters by fixing a measuring tape to the wall and weight was measured in kilograms by a portable analogue weighing scale. Biceps, triceps and suprailiac skin fold measurements were collected by using digital fat track II skin fold caliper. Mid upper arm (MUAC), waist and hip measurements were taken into account using non-stretchable measuring tape.

\section{Neonatal Measurements}

Weight at birth was taken by infant pan scale whereas length was collected by using an infant-o-meter. Abdominal, head and mid arm measurements were collected by using a non-stretchable measuring tape [12]. A digital body fat caliper was used to measure biceps, triceps and sub scapular skin fold.

\section{Dietary Assessment}

Dietary assessment was carried out in a face-to-face interview with pregnant women participating in the study, using a Food Frequency Questionnaire (FFQ) consisting of about 125 food items and 24 hour dietary recall (DR) in order to assess the frequency of consumption of specific food or category of food [13]. Fifty percent of early pregnancy assessments were made during 5-8 weeks of gestation and other 50\% during 9-13 weeks of gestation. In the $3^{\text {rd }}$ trimester group $88 \%$ of the dietary assessments were made during 34 to 40 weeks of gestation. FFQ and $24 \mathrm{hrs}$ DR were designed in accordance with recommended dietary guidelines provided by the National Institutes of Health (NIH), United States Department of Agriculture (USDA) and
Food and Agriculture Organization of the United Nations (FAO) [14]. Pakistani Food Composition Tables were used to generate estimates of daily intakes of total energy [15]. Bread, fruit, vegetables, milk and meat were used as different food groups. Food group consumption in the mothers was assessed by using Food Guide Pyramid [16]. A reference table of weight for height according to the week of pregnancy was used to categorize mothers as under nourished and well-nourished groups [17].

\section{Statistical Analysis}

SPSS version 13.0 was used to record and analyze study data. Dietary intake was evaluated as frequency of consumption of food groups and total energy intake as mean of nutrients in first and third trimester. Data presented as Mean \pm SD. Pearson's correlation coefficient was used to investigate the relationship between maternal dietary composition during pregnancy and birth characteristics of the newborns. Results with $\mathrm{P}$ value less than 0.05 were considered statistically significant.

\section{RESULTS}

Dietary profile of 100 mothers (48 from $1^{\text {st }}$ trimester and 52 from $3^{\text {rd }}$ trimester) was recorded. Our results reported that most of the mothers regardless of trimester and nutritional status, were consuming less than the recommended amount of various foods. Bread and cereal intake of only $44 \%$ of mothers was according to the recommendation while $56 \%$ were consuming less than the recommended servings. Fruit and vegetable intake was incredibly low, pertaining to 96 and $93 \%$ of the study population respectively. Eighty percent of mothers were consuming less than a serving of meat per day whereas $94 \%$ had low milk consumption per day.

Table 1 shows baseline characteristics of pregnant women and newborns included in the study. Weight and Body Mass Index (BMI) of well-nourished mothers were significantly higher in both trimesters $(p<0.05)$. Statistically significant difference was seen in skin fold measurement of undernourished and well-nourished mothers in first trimester $(p<0.05)$ whereas in $3^{\text {rd }}$ trimester group it was similar in both groups. Among the neonates, mean birth weight was $2.89 \pm 0.42(\mathrm{~kg})$.

Energy and food group intake of pregnant females in early and late pregnancy is presented in Table 2. Mean calorie intake of both groups was less than the recommended dietary allowance for pregnant women per day. Among the food groups, only bread and cereal intake was fairly adequate in both trimesters while consumption of other groups was lower than the recommended amount of servings per day.

Pearson correlation coefficient was used to assess the association between maternal dietary intake during pregnancy and anthropometric measurements of the newborns at birth. A statistically significant negative association was noted between maternal milk intake in wellnourished group and sub scapular skin fold thickness of the newborn at birth. Similarly, consumption of milk in undernourished mothers was also found associated negatively with mid upper arm circumference of the newborns $(p<0.05)$. Though not significant but a weak correlation was noted between daily fruit and meat intake in 
Table 1. Characteristics of the pregnant women and newborns included in the study.

\begin{tabular}{|l|c|c|c|c|c|c|}
\hline \multicolumn{1}{|c|}{ Mothers } & \multicolumn{3}{c|}{$1^{\text {st }}$ Trimester } & \multicolumn{2}{c|}{$3^{\text {rd }}$ Trimester } \\
\hline \multicolumn{1}{|c|}{ Nutritional Status } & Undernourished & Well-Nourished & p-Value & Undernourished & Well-Nourished \\
\hline \hline N & 21 & 27 & & 22 & 30 \\
\hline Age (years) & $27.12 \pm 5.77$ & $28.63 \pm 6.63$ & 0.387 & $25.11 \pm 4.07$ & $28.31 \pm 3.61$ & $* 0.003$ \\
\hline Weight $(\mathrm{kg})$ & $47.64 \pm 5.27$ & $65.37 \pm 11.75$ & $* 0.000$ & $54.03 \pm 7.33$ & $69.29 \pm 5.92$ & $* 0.000$ \\
\hline Body Mass Index $\left(\mathrm{kg} / \mathrm{m}^{2}\right)$ & $20.0 \pm 2.30$ & $26.74 \pm 4.61$ & $* 0.000$ & $22.67 \pm 2.88$ & $28.37 \pm 2.17$ & $* 0.000$ \\
\hline Biceps (mm) & $12.27 \pm 6.49$ & $20.10 \pm 7.33$ & $* 0.000$ & $9.45 \pm 6.76$ & $10.09 \pm 6.31$ & 0.722 \\
\hline Triceps $(\mathrm{mm})$ & $16.62 \pm 6.43$ & $26.30 \pm 6.94$ & $* 0.000$ & $14.88 \pm 6.50$ & $19.17 \pm 10.61$ & 0.082 \\
\hline Suprailiac $(\mathrm{mm})$ & $11.75 \pm 5.62$ & $17.16 \pm 5.74$ & $* 0.002$ & $8.68 \pm 5.74$ & $11.91 \pm 7.71$ & 0.088 \\
\hline MUAC $(\mathrm{cm})$ & $23.16 \pm 4.85$ & $28.88 \pm 4.07$ & $* 0.000$ & $24.69 \pm 2.92$ & $30.03 \pm 12.35$ & $* 0.036$ \\
\hline
\end{tabular}

\begin{tabular}{|l|c|c|c|c|}
\hline \multicolumn{1}{|c|}{ Babies } & Overall & Undernourished & Well-Nourished & p-Value \\
\hline \hline $\mathrm{N}$ & 52 & 22 & 30 & 0.18 \\
\hline Birth weight $(\mathrm{kg})$ & $2.89 \pm 0.42$ & $2.81 \pm 0.35$ & $2.97 \pm 0.46$ & 0.20 \\
\hline Ponderal index $\left(\mathrm{kg} / \mathrm{m}^{2}\right)$ & $33.44 \pm 12.75$ & $35.68 \pm 13.5$ & $31.20 \pm 11.7$ & 0.32 \\
\hline Gestational age at birth (weeks) & $39.27 \pm 1.53$ & $39.48 \pm 1.55$ & $39.06 \pm 1.53$ & \\
\hline
\end{tabular}

Data presented as Mean \pm SD.

MUAC- Mid upper arm circumference.

$* \mathrm{P}<0.05$.

well-nourished mothers and sub scapular skin fold $(\mathrm{r}=0.40)$ and mid upper arm circumference $(\mathrm{r}=0.41)$ of the newborns respectively (Table 3). Furthermore, an association was also observed between maternal weight and BMI and weight of neonates at birth $(\mathrm{p}<0.008)$.

Table 2. Calorie and food group intake of mothers assessed by 24 hrs. Dietary recall (DR).

\begin{tabular}{|c|c|c|c|}
\hline Intake & $\mathbf{1}^{\text {st }}$ Trimester & $\mathbf{3}^{\text {rd }}$ Trimester & Recommendation \\
\hline \hline Calories & $1436.54 \pm 446.8$ & $1406.7 \pm 316.0$ & $* 2510$ \\
\hline Food groups & & & \\
\hline Bread \& cereals & $6.86 \pm 2.61$ & $7.56 \pm 2.83$ & $\dagger 6-11$ \\
\hline Milk & $1.00 \pm 0.71$ & $0.94 \pm 0.8$ & $\dagger 2-3$ \\
\hline Meat & $1.61 \pm 0.98$ & $1.87 \pm 1.27$ & $\dagger 2-3$ \\
\hline Vegetables & $1.31 \pm 0.94$ & $1.38 \pm 0.94$ & $\dagger 3-5$ \\
\hline Fruits & $0.85 \pm 0.93$ & $0.9 \pm 0.97$ & $\dagger 3-4$ \\
\hline Fats (gm.) & $65.5 \pm 29.6$ & $63.21 \pm 23.6$ & $* 65$ \\
\hline
\end{tabular}

$\mathrm{DR}=$ dietary recall.

*RDA= Recommended dietary allowance [14].

$\dagger$ Recommended servings [14].

Data presented as Mean \pm SD

Figs. $(1,2)$ show comparison of energy intake in early and late pregnancy between undernourished and wellnourished mothers according to $24 \mathrm{hrs}$ DR and FFQ. Energy intake of undernourished mothers in first trimester group assessed by FFQ as well as by $24 \mathrm{hrs}$ DR was significantly low compared to well-nourished mothers $(p<0.001)$ whereas it was similar in $3^{\text {rd }}$ trimester group.

\section{DISCUSSION}

Our study showed that energy consumption of mothers in early as well as in late gestation was incredibly low with reference to the recommended dietary allowance for pregnant mothers in Pakistan [18]. Our results are in line with the findings of other studies conducted in Pakistan. Their results also indicated low calorie consumption in pregnant population compared to the recommended dietary allowance (RDA) during pregnancy [19]. Another study also found low energy intake in mothers compared to RDA, however mean intake in their population was higher compared to our study participants [20].

The trend of different food group intake in pregnant mothers was also assessed in the study. We observed that pregnant mothers regardless of trimester and nutritional status were consuming less than recommended servings of various food groups. Mean intake of only bread and cereal group was according to the recommended servings per day while consumption of other groups e.g. fruit, vegetables, milk and meat was found very low in both trimesters $\left(1^{\text {st }}\right.$ and $3^{\text {rd }}$ trimester). This trend of food group intake in our study participants has been reflecting the dietary habits of Pakistani population where women are not used to take milk and fruit in every day meal while carbohydrates and fats are the main components of the daily cooking [21].

Weight and crown heel length at birth are commonly used anthropometrics to evaluate the growth of the fetus during intrauterine life. However, other parameters such as head circumference, abdominal circumference and skin fold measurements are equally important in determining the intrauterine development of the fetus. Therefore, in addition to the weight and length other anthropometric measurements of newborns were also taken into account to look at the 
Table 3. Correlation coefficients of neonatal anthropometrics with maternal dietary intake.

\begin{tabular}{|c|c|c|c|c|c|c|}
\hline \multicolumn{7}{|c|}{ Undernourished } \\
\hline Parameters & Birth Weight & Crown Heel Length & Triceps Skin Fold & Sub Scapular Skin Fold & MUAC & Head Circumference \\
\hline Bread & $-0.12(0.56)$ & $0.12(0.56)$ & $0.11(0.58)$ & $-0.09(0.65)$ & $-0.20(0.33)$ & $0.13(0.51)$ \\
\hline Vegetable & $0.04(0.82)$ & $-0.18(0.38)$ & $0.05(0.81)$ & $0.03(0.86)$ & $-0.06(0.76)$ & $0.06(0.76)$ \\
\hline Fruit & $-0.15(0.47)$ & $0.05(0.79)$ & $-0.36(0.09)$ & $-0.13(0.53)$ & $-0.32(0.12)$ & $-0.34(0.09)$ \\
\hline Meat & $-0.04(0.83)$ & $0.07(0.73)$ & $-0.25(0.25)$ & $-0.31(0.13)$ & $-0.03(0.87)$ & $-0.16(0.44)$ \\
\hline Milk & $-0.21(0.32)$ & $0.02(0.90)$ & $-0.13(0.55)$ & $0.26(0.22)$ & $-0.54 *(0.00)$ & $0.06(0.77)$ \\
\hline Fats & $0.09(0.67)$ & $0.077(0.71)$ & $0.11(0.60)$ & $0.10(0.64)$ & $0.10(0.60)$ & $0.08(0.68)$ \\
\hline \multicolumn{7}{|c|}{ Well-Nourished } \\
\hline Bread & $-0.03(0.70)$ & $-0.23(0.27)$ & $-0.07(0.95)$ & $0.14(0.50)$ & $-0.07(0.80)$ & $0.06(0.76)$ \\
\hline Vegetable & $-0.15(0.62)$ & $-0.37(0.13)$ & $-0.04(0.74)$ & $-0.05(0.92)$ & $-0.06(0.90)$ & $0.19(0.36)$ \\
\hline Fruit & $0.37(0.08)$ & $0.07(0.73)$ & $0.29(0.18)$ & $0.40(0.06)$ & $0.23(0.29)$ & $0.169(0.41)$ \\
\hline Meat & $-0.10(0.55)$ & $-0.00(0.98)$ & $0.31(0.15)$ & $-0.22(0.13)$ & $0.41(0.05)$ & $0.372(0.06)$ \\
\hline Milk & $-0.15(0.24)$ & $-0.30(0.60)$ & $-0.30(0.16)$ & $-0.46 *(0.02)$ & $-0.26(0.23)$ & $0.02(0.91)$ \\
\hline Fats & $0.09(0.66)$ & $-0.02(0.89)$ & $0.13(0.52)$ & $0.34(0.09)$ & $0.01(0.94)$ & $0.02(0.89)$ \\
\hline
\end{tabular}

Data presented as Pearson's r (P value) $* \mathrm{P}<0.05$.

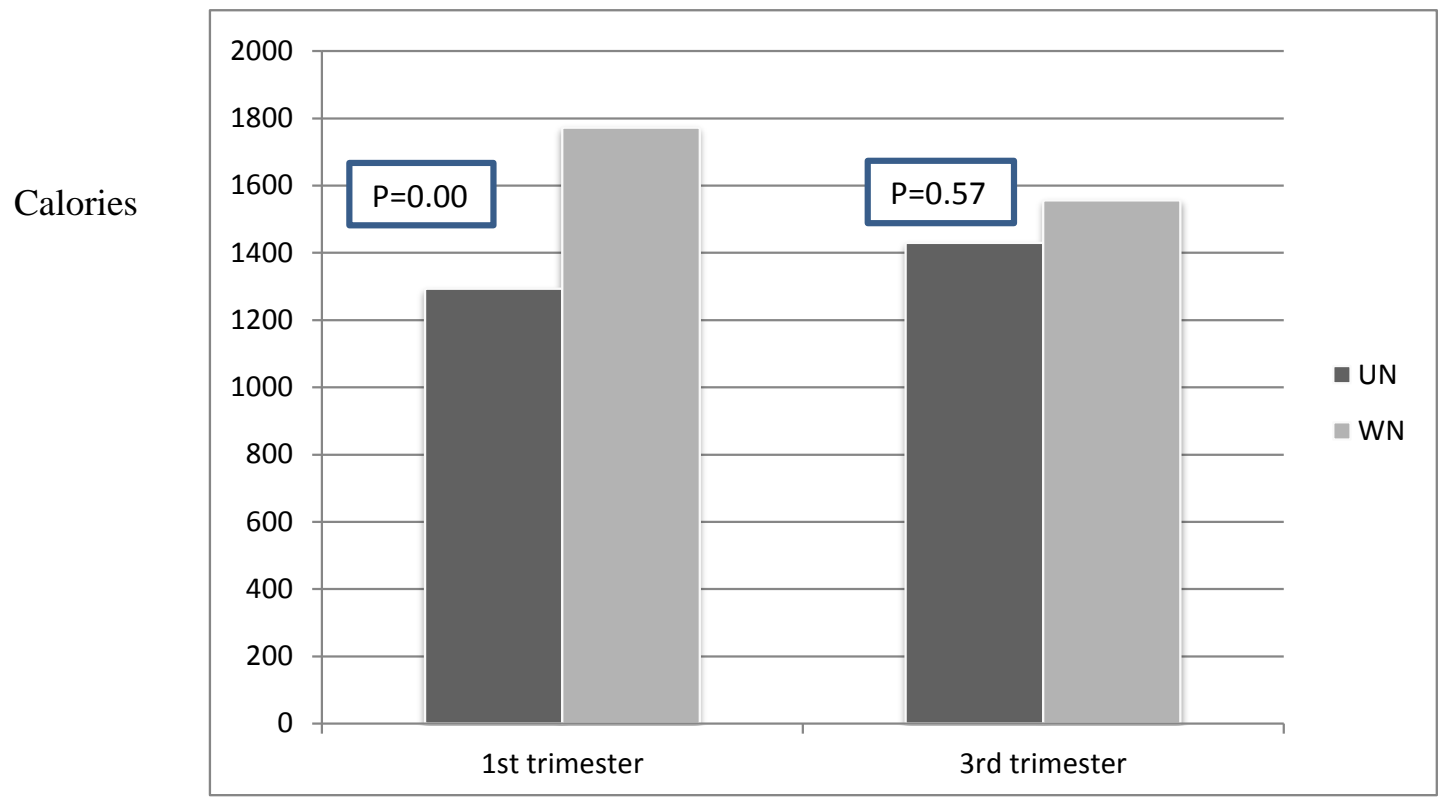

UN: Under nourished

WN: Well nourished

Fig. (1). Comparison of energy intake between maternal groups according to $24 \mathrm{hr}$ Dietary Recall.

association between fetal growth and dietary intake in mothers during pregnancy. Our results reported an inverse relationship between sub scapular skin fold thickness of the newborns and maternal consumption of milk in well nourished group. Furthermore, intake of milk in undernourished mothers was also found associated significantly with mid upper arm circumference (MUAC) of the offspring at birth. Some European studies also observed an association between milk consumption in pregnant mothers and anthropometrics measurements of the newborns like weight, crown heel length and abdominal measurements at birth [22-24]. Moreover, their results were significant even after adjusting for confounders. However, we did not observe such type of association in our study population. Low milk consumption in our population might be one possible explanation of this difference. Moreover, small sample size of our study may be another reason for this difference. 


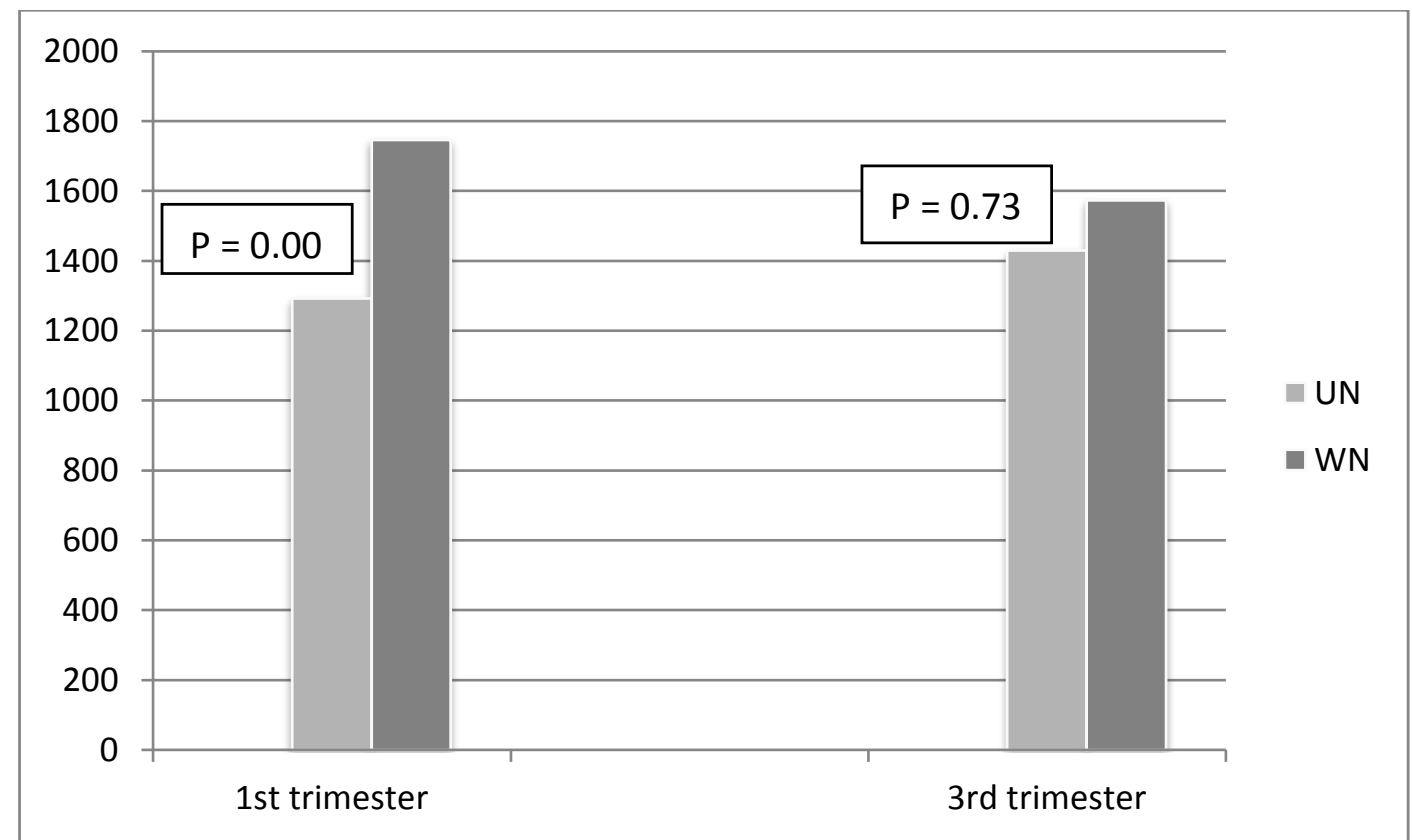

\section{UN: Undernourished}

WN: Well Nourished

Fig. (2). Comparison of energy intake between maternal groups according to Food Frequency Questionnaire (FFQ).

Interestingly, we found that energy consumption in undernourished mothers was low compared to wellnourished mothers only in $1^{\text {st }}$ trimester whereas in $3^{\text {rd }}$ trimester group it was similar in both nutrition categories. This finding needs to be explored further in future studies with large sample size.

\section{CONCLUSION}

In this study, we observed that overall energy intake was low in undernourished compared to well-nourished mothers during early gestation. Moreover, maternal dietary intake and nutritional status during pregnancy have impact on fetal body composition.

\section{CONFLICT OF INTEREST}

The authors confirm that this article content has no conflict of interest.

\section{ACKNOWLEDGEMENTS}

We acknowledge valuable support of research department of Baqai Institute of Diabetology and Endocrinology, especially Ms. Fariha Shaheen (Statistician) and Mr. Bilal Tahir (Research Coordinator) for their help in data entry and analysis. We sincerely thank all the participants who made this study possible.

\section{REFERENCES}

[1] Cesar GV, Linda A, Caroline F, et al. For the maternal and child undernutrition study group capital. Lancet 2008; 371: 340-57.

[2] Darnton H, Nishida C, James WP. A life course approach to diet, nutrition and the prevention of chronic diseases. Public Health Nutr; 7(1A): 101-21.

[3] Tianan J, Parul C, Subarna K. K, Lee W, Keith PW. Micronutrient deficiencies in early pregnancy are common, concurrent and vary by season among rural nepali pregnant women. J Nutr 2005; 135: 1106-12.
[4] Vivienne MM, Michael JD, Kristyn JW, Anthony W, Jeffrey SR. Dietary composition of pregnant women is related to size of the baby at birth. J Nutr 2004; 134: 1820-26.

[5] Maternal, newborn, child and adolescent health: care of the preterm and/or low-birth-weight newborn. World Health Organization 2012.

[6] Low birth weight country, regional and global estimates. UNICEF: New York 2004

[7] Cita YP. The relationship between demographic factors and low birth weight infants. Int J Res Nurs 2010; 1: 25-8.

[8] Sophie EM, Fehmida J, Rifat A, Shousun CS, Andrew MP, Lars $\AA$ A. Birth weight predicts response to vaccination in adults born in an urban slum in Lahore, Pakistan. Am J Clin Nutr 2004; 80: 453-9.

[9] Langley AJE. Relationship between maternal nutrient intakes in early and late pregnancy and infant's weight and proportions at birth: prospective cohort study. J R Soc Promot Health 2003; 123(4): 210-6.

[10] Ahmed AAS. Diet history and birth weight relationship among Saudi pregnant women. Pak J Med Sci 2007; 23(2); 1-6

[11] Khoushabi, Saraswathi G. Association between maternal nutrition status and birth weight of neonates in selected hospitals in Mysore city, India. Pak J Nutr 2010; 9(12); 1124-30.

[12] Sarah HK, Krishnaveni GV, Veena SR, et al. Diet patterns are associated with demographic factors and nutritional status in South Indian children: diet patterns of Indian children. Matern Child Nutr 2013; 10: 145-58.

[13] Thompson FE, Amy FS. Dietary assessment methodology. In: Coulston AM, Rock CL, Monsen ER, Eds. Nutrition in the prevention and treatment of disease. San Diego: Academic Press 2008.

[14] Food and agriculture organization of United Nations Website. Available at: http://www.fao.org/; http://www.fns.usda.gov/; http://www.nih.gov/

[15] Food composition table for Pakistan (revised 2001). Ministry of planning and development, Government of Pakistan.

[16] Song YP, Suzanne PM, Lynne RW, et al. Dietary patterns using the food guide pyramid groups are associated with socio-demographic and lifestyle factors: the multiethnic cohort study. J Nutr 2005; 135(4): 843-9.

[17] Miguel G, Peter J, Bernard S. Anthropometric assessment of nutritional status in pregnant women: a reference table of weight for height by weeks of pregnancy. Am J Clin Nutr. 1982; 35: 60916. 
[18] Shoberi F, Khyrunnisa B, Nazari M. A prospective study of maternal hemoglobin status of Indian women during pregnancy and pregnancy outcome. Nutr Res 2006; 26: 209-13.

[19] Ijlal F. Iron deficiency anemia in the female and children of the Northern areas of Pakistan. PhD thesis. Department of Biological Sciences, Quaid-e-Azam University: Islamabad, Pakistan 2005.

[20] Tehzeeb Z, Farwa R, Samina J, Shami SA, Nasira T, Sarwat J. Effects of maternal macronutrients intake in $3^{\text {rd }}$ trimester of normal pregnancy on maternal weight gain neonatal birth weight of full term neonates. Rawal Med J 2011; 36: 1-14.
[21]
Thirty years of polling on eating habits of Pakistanis (1980-2010). Perceptions and preferences of Pakistani public. A Gallup Pakistan Report 2011

Oslen SF, Halldorson TI, Willet WC. Milk consumption during pregnancy is associated with increased infant size at birth: prospective cohort study. Am J Clin Nutr 2007; 86: 1104-10.

Rao S, Yajnik CS, Kanade A. Intake of micronutrient-rich foods in rural Indian mothers is associated with the size of their babies at birth: Pune maternal nutrition study. J Nutr 2001; 131: 1217-24.

Denise HM, Rob MVD, Sten PW, et al. Maternal milk consumption, fetal growth, and the risks of neonatal complications: the Generation R study. Am J Clin Nutr 2011; 94: 501-9.

(C) Shaikh et al:; Licensee Bentham Open.

This is an open access article licensed under the terms of the Creative Commons Attribution Non-Commercial License (http://creativecommons.org/licenses/ by-nc/3.0/) which permits unrestricted, non-commercial use, distribution and reproduction in any medium, provided the work is properly cited. 